\title{
Hypolobocera guayaquilensis (Decapoda: Pseudothelphusidae): A New Crab Intermediate Host of Paragonimus mexicanus in Manabí Province, Ecuador
}

\author{
Manuel Calvopina', Daniel Romero-Alvarez², Melina Rendon³, Hidekazu Takagi", Hiromu Sugiyama ${ }^{5, *}$ \\ 'OneHealth Group, Escuela de Medicina, Facultad de Ciencias de la Salud, Universidad de las Americas (UDLA), Quito, Ecuador; '²Department of

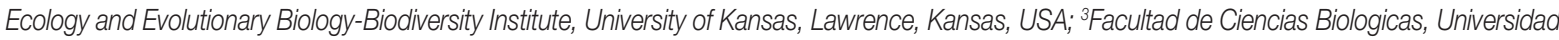 \\ Central del Ecuador, Quito, Ecuador; ${ }^{4}$ Department of Microbiology and Immunology, Aichi Medical University School of Medicine, Aichi, Japan; \\ ${ }^{5}$ Department of Parasitology, National Institute of Infectious Diseases, Tokyo, Japan
}

\begin{abstract}
To determine that Paragonimus sp. is actively transmitted in a tropical area of the Pacific region of Ecuador where human cases of pulmonary paragonimiasis have recently been documented, a total of 75 freshwater crabs were collected from 2 different streams in the Pedernales area of Manabí Province, Ecuador. All collected crabs were identified as Hypolobocera guayaquilensis based on morphological characteristics of the male gonopods. The hepatopancreas of each crab was examined by compressing it between 2 glass plates followed by observation under a stereomicroscope. Excysted Paragonimus metacercariae were detected in 39 (52.0\%) crabs and their densities varied from 1 to 32 per infected crab. There was a positive relationship between crab size and metacercarial density. Sequences of the second internal transcribed spacer region of the ribosomal RNA gene of the Paragonimus metacercariae obtained in this study were identical to those of Paragonimus mexicanus deposited in the DDBJ/EMBL/GenBank database. Thus, the present study is the first to confirm that the crab species $H$. guayaquilensis is the second intermediate host of $P$. mexicanus in Manabí Province, Ecuador. Because this crab might be the possible source of human infections in this area, residents should pay attention to improper crab-eating habits related with a neglected parasitic disease, i.e., paragonimiasis.
\end{abstract}

Key words: Paragonimus mexicanus, Paragonimus kellicotti, Hypolobocera sp., crab, intermediate host, trematode, lung fluke, food-borne disease, PCRRFLP, Ecuador

\section{INTRODUCTION}

Paragonimus species are dispersed globally, but are most frequently found in Asia, Africa, and the Americas, where nine of about 50 nominal species are known to infect humans. In the USA, Paragonimus kellicotti is known to cause human illness, while Paragonimus mexicanus is accepted as a pathogenic species in Central and South American countries [1-3]. The metacercariae of $P$. mexicanus are unique in lacking a cyst wall, thus being very motile inside the body of crab hosts [4]. Recent research on the scanning electron microscope-based morphological and molecular features of Paragonimus metacercariae from Mexico has evidenced P. mexicanus as a species complex,

\footnotetext{
- Received 4 December 2017, revised 22 March 2018, accepted 2 April 2018.

*Corresponding author (hsugi@nih.go.jp)

(C) 2018, Korean Society for Parasitology and Tropical Medicine

This is an Open Access article distributed under the terms of the Creative Commons

Attribution Non-Commercial License (http://creativecommons.org/licenses/by-nc/4.0) which permits unrestricted non-commercial use, distribution, and reproduction in any

medium, provided the original work is properly cited.
}

and P. ecuadoriensis was recognized as possible cryptic/sibling species [5].

In Ecuador, P. ecuadoriensis was described as a new species based on the distinct morphology of its ovary and testis in relation to that of P. mexicanus, Paragonimus inca, and Paragonimus peruvianus [6]. However, further comparative studies revealed that $P$. ecuadoriensis is a junior synonym of $P$. mexicanus $[4,7]$. In Manabí Province, adult parasites obtained from experimentally infected animals showed similar morphological characteristics to P. mexicanus [3]. In Esmeraldas Province, bordering Manabí, isolated metacercariae were also identified as $P$. mexicanus by sequencing the second internal transcribed spacer (ITS2) region of ribosomal RNA gene [2].

Two siblings showing pulmonary symptoms such as productive coughs with bloody sputa were seen as outpatients in a hospital in Quito. They came from the Pedernales area in Manabí Province and had a history of consuming undercooked freshwater crabs captured in tributaries of the Cheve River. Accordingly, they were both diagnosed with pulmonary 
paragonimiasis and then successfully treated. The discovery of these cases prompted us to carry out an intensive field survey around the Cheve River to determine (1) the presence of active transmission of Paragonimus in the area, (2) the Paragonimus sp. involved, and (3) the identification of crab hosts and their respective infection rate, which are presented in this study.

\section{MATERIALS AND METHODS}

\section{Study site and crab collection}

Freshwater crabs, Hypolobacera guayaquilensis, were collected by local people in August 2011 in 2 tributary streams of the Cheve River flowing through the Pedernales area of Manabí Province, northwestern Pacific Coast of Ecuador (Fig. 1). This region, located between 120 and $500 \mathrm{~m}$ above sea level, and at latitude $0.138633^{\circ} \mathrm{N}$ and longitude $79.874267^{\circ} \mathrm{W}$, is a seasonal green forest of the Equatorial Pacific Coast Range in Chongon-Colonche Mountains. Selected geographical areas are dedicated to agriculture and cattle ranching [8].

To collect crabs, an active search was performed in advance in the 2 tributaries of the Cheve River, which descends from the mountains. Shallow and slowly flowing streams with rocky and muddy areas are the typical habitats where crab burrows are found. Collected crabs were transferred to the laboratories in Quito and maintained alive in 20-L plastic containers with $2 \mathrm{~L}$ of river water at about $25^{\circ} \mathrm{C}$ (room temperature) until examined.

\section{Examination of crabs for Paragonimus metacercariae}

The crabs were sacrificed using thermal shock by immersing them in water at about $2^{\circ} \mathrm{C}$ for $10 \mathrm{~min}[9]$. Then, the genitalia of each crab was examined for gender and species identification. Next, the maximum width of the carapace was measured using a caliper. After that, the carapace was removed from the posterior end of the body and only the hepatopancreas was removed as previously described [10]. The hepatopancreas was finally compressed between 2 glass plates $(6 \times 10 \times 0.2 \mathrm{~cm})$, which were examined under a dissecting microscope (CRX-32, Olympus, Tokyo, Japan). When Paragonimus metacercariae were detected, the glass plate was carefully removed to recover the metacercariae using teasing needles or tweezers. The isolated metacercariae were transferred into a Petri dish containing physiological saline solution using a capillary pipet. After taking photographs under a microscope (DP71, Olympus), Paragonimus metacercariae were preserved in $70 \%$ ethanol for molecular analysis.

\section{Molecular identification of metacercariae}

The molecular characterization of the metacercariae was performed by DNA isolation, amplification of the ITS2 region by PCR, and PCR-restriction fragment length polymorphism (PCR-RFLP); all processed material was sequenced as previously described [9]. Specifically, the primers used for PCR amplification and sequencing were 3S (forward, 5'-GGTACCGGTGGATCACTCGGCTCGTG-3; [11]) and A28 (reverse, 5'-GGGATCCTGGTTAGTTTCTTTTCCTCCGC-3'; [12]). The

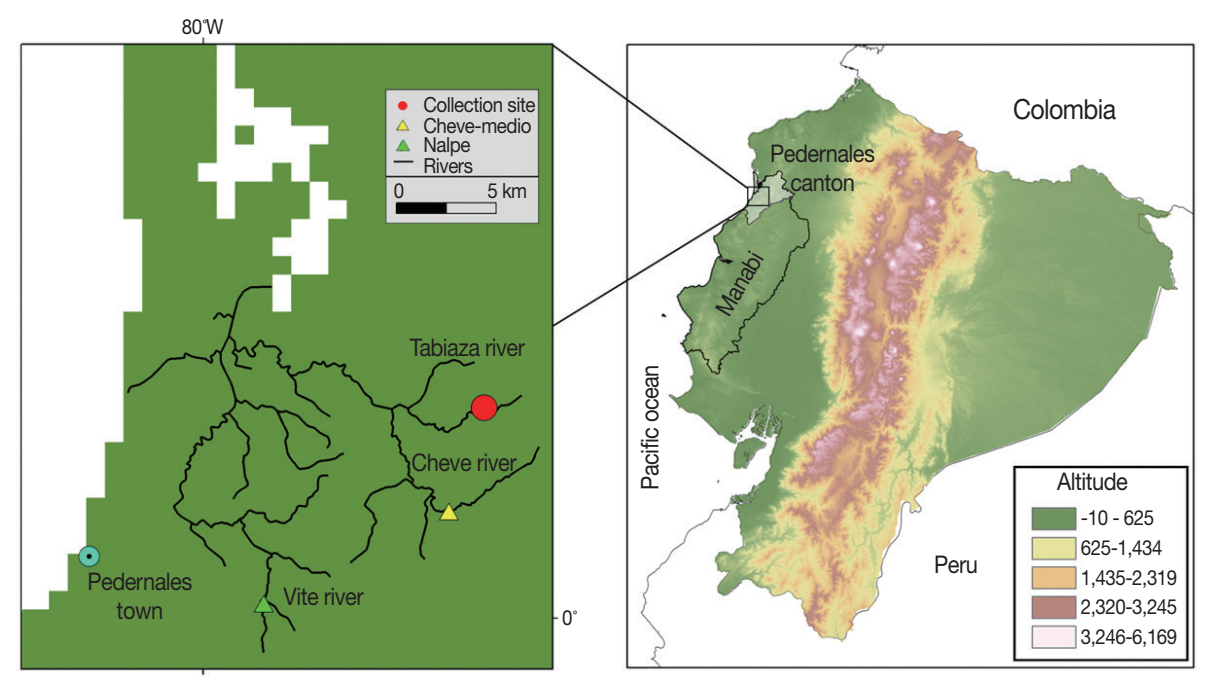

Fig. 1. Map of the study area in the Pedernales area, Manabí Province, Ecuador. The Cheve River, collection site, and Cheve Medio community are indicated in the left panel. Cheve Medio is located $-20 \mathrm{~km}$ inland from nearby Pedernales on the coast of the Pacific Ocean. 
PCR amplification was conducted using $0.25 \mu \mathrm{M}$ of each primer and $2.5 \mathrm{U}$ of Phusion High-Fidelity DNA Polymerase (Thermo Fisher Scientific, Waltham, Massachusetts, USA). The PCR was carried out on a thermal cycler (TaKaRa PCR Thermal Cycler Dice Gradient, Takara Bio, Shiga, Japan), with 30 cycles of $98^{\circ} \mathrm{C}$ for $10 \mathrm{sec}, 55^{\circ} \mathrm{C}$ for $10 \mathrm{sec}$, and $72^{\circ} \mathrm{C}$ for $15 \mathrm{sec}$. An initial denaturation and final extension were performed at $98^{\circ} \mathrm{C}$ for $30 \mathrm{sec}$ and at $72^{\circ} \mathrm{C}$ for $7 \mathrm{~min}$, respectively. For the PCR-RFLP,

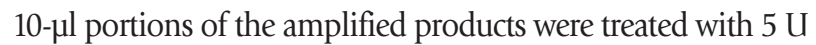
of the restriction enzyme Hinc II (New England Biolabs, Ipswich, Massachusetts, USA) at $37^{\circ} \mathrm{C}$ for $1 \mathrm{hr}$. Then, the amplicons with or without enzymatic treatment were separated by electrophoresis on $2 \%(\mathrm{w} / \mathrm{v})$ agarose gels. All amplified products were sequenced using the corresponding primers and the BigDye Terminator v3.1 Cycle Sequencing Kit (Thermo Fisher Scientific) on an automated sequencer (3730xl DNA Analyzer, Thermo Fisher Scientific). Sequences were aligned and compared using GENETYX-Win software (Ver. 13, Genetyx Co., Tokyo, Japan). Following the procedures described above, we also processed metacercariae of $P$. kellicotti isolated from crayfish collected in Missouri, USA [13], for comparison purposes.

\section{Statistical analyses}

A Poisson regression was performed to analyze the relationship between carapace size and the number of Paragonimus metacercariae per crab. We tested for a non-zero-slope term (the measure of effect) using a likelihood ratio test. Differences between gender and infection and between carapace size (quartiles) and infection were determined using a Chi-square test. All analyses were performed in R software (https://www.rproject.org/) considering $\alpha=0.05$.

\section{Ethics}

Ethical approval of the study was given by the Ethics Committee of the Universidad Central del Ecuador (License number LEC IORG 0001932, FWA 2482, IRB 2483.COBI-AMPHI-0064-11).

\section{RESULTS}

Of a total of 75 crabs examined, 50 were males (66.7\%) and 25 were females (33.3\%). All male crabs had gonopods with morphological features characteristic $H$. guayaquilensis. The average carapace size of the 75 crabs was $3.5 \mathrm{~cm}( \pm 1.18 \mathrm{~cm}$, $\mathrm{SD})$, ranging from 1.3 to $5.7 \mathrm{~cm}$. Of the 75 crabs, 39 (52.0\%) were infected with Paragonimus metacercariae. Of these crabs, $24(32.0 \%)$ were males and 15 (20.0\%) were females; no statistically significant relationship was detected between crab gender and metacercarial presence $(P=0.46$; Table 1$)$.

All metacercariae were excysted, dorso-ventrally flattened, and very motile under the microscope. The excretory bladder was clearly observed in the midline of each metacecarial body, between the right and left intestines, which was yellow in color and connected to the oral sucker through the pharynx. These morphological features were in accordance with those of $P$. mexicanus (Fig. 2).

Using PCR amplification, ITS2 products of about 520 base pairs (bp) were generated from the DNA samples prepared from the excysted metacercariae (Fig. 3; lane 1). The sequence analysis of the PCR amplicons revealed that the amplified product was $461 \mathrm{bp}$ (without primer sequences). The sequences obtained were identical to those previously obtained $P$. mexicanus metacercariae (DDBJ/EMBL/GenBank accession

Table 1. Prevalence of Paragonimus mexicanus metacercariae according to crab gender and carapace size group

\begin{tabular}{|c|c|c|c|c|c|c|}
\hline & \multicolumn{3}{|c|}{ No. (\%) of crabs } & \multirow{2}{*}{$\mathrm{Chi}^{2}$} & \multirow{2}{*}{ Degrees of freedom } & \multirow{2}{*}{$P$-value } \\
\hline & Total & Positive & Negative & & & \\
\hline \multicolumn{7}{|c|}{ Crab gender } \\
\hline Male & $50(66.7)$ & $24(32.0)$ & $26(34.7)$ & 0.54 & 1 & 0.46 \\
\hline Female & 25 (33.3) & $15(20.0)$ & $10(13.3)$ & & & \\
\hline Overall & $75(100)$ & $39(52.0)$ & $36(48.0)$ & & & \\
\hline \multicolumn{7}{|c|}{ Carapace size (cm) } \\
\hline $1.3-2.9$ & 19 (25.3) & $5(6.7)$ & $14(18.7)$ & 8.96 & 3 & $0.03^{\mathrm{a}}$ \\
\hline $3-3.5$ & $20(26.7)$ & $10(13.3)$ & 10 (13.3) & & & \\
\hline 3.6-4.4 & $20(26.7)$ & $12(16.0)$ & $8(10.7)$ & & & \\
\hline$>4.4$ & $16(21.3)$ & $12(16.0)$ & 4 (5.3) & & & \\
\hline Overall & 75 (100) & 39 (52.0) & $36(48.0)$ & & & \\
\hline
\end{tabular}

No difference in the infection rate was found between genders, but significant difference was found among carapace size groups.

asignificance $=P<0.05$. 


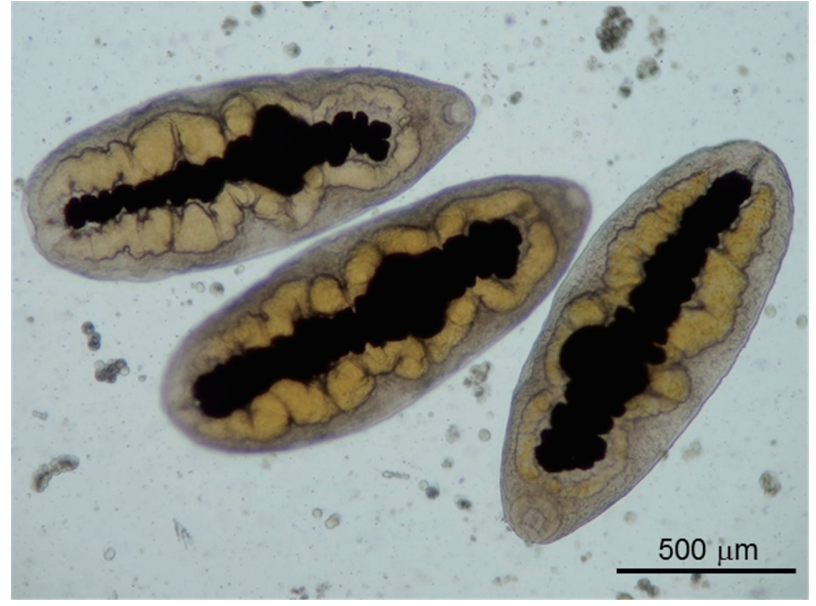

Fig. 2. Photomicrograph of Paragonimus metacercariae. Metacercariae isolated from the hepatopancreas of the crab Hypolobocera guayaquilensis lack cyst walls.

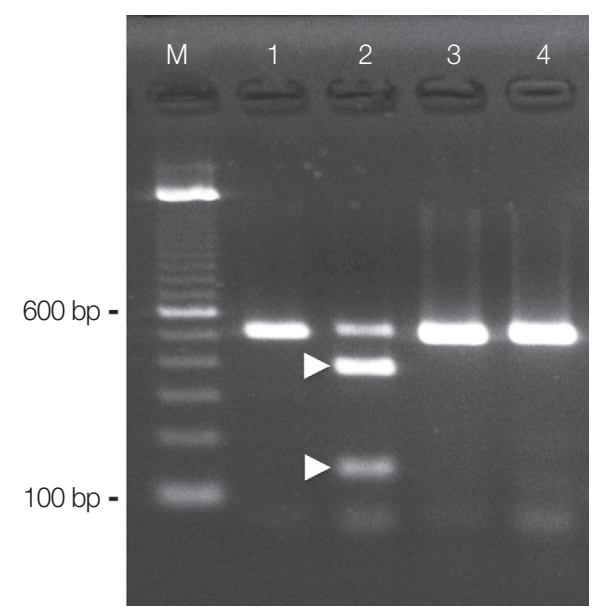

Fig. 3. Species identification by PCR-RFLP. PCR products from the ITS2 region of the nuclear ribosomal RNA gene were obtained from metacercariae of Paragonimus mexicanus (lane 1 and lane 2) and Paragonimus kellicotti (lane 3 and lane 4). The restriction endonuclease Hinc II used for RFLP digested the amplicons from $P$. mexicanus (lane 2, showing 2 fragments, $380 \mathrm{bp}$ and $140 \mathrm{bp}$, arrow heads), but not the amplicons from $P$. kellicotti (lane 4, showing an undigested single fragment of $520 \mathrm{bp}$ ).

number: AB308377) and eggs (AB308378) occurring in Ecuador [14]. Therefore, the nucleotide sequence obtained in this study has been deposited as the metacercarial stage of $P$. mexicanus in the DDBJ/EMBL/GenBank database under the accession number LC317061.

Species discrimination by RFLP of the PCR amplicons obtained from the excysted metacercariae of $P$. mexicanus using the endonuclease Hinc II resulted in 2 fragments of expected sizes (about 380 and 140 bp; Fig. 3; lane 2). Similarly, ITS2

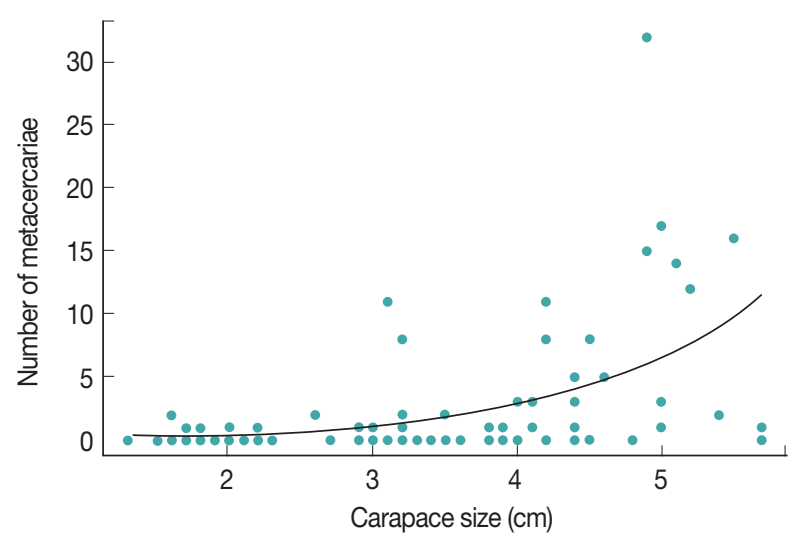

Fig. 4. Relationship between carapace size and number of metacercariae. We found a significant positive relationship between the number of metacercariae (blue dots) and carapace size $(P<0.001$; intercept $=-2.42$, standard error $=0.34$; slope $=0.86$, standard error $=0.074)$. The black curve represents the expected number of metacercariae (based on crab carapace size) under the Poisson regression model.

products of about $520 \mathrm{bp}$ were also generated from the DNA samples prepared from P. kellicotti metacercariae (Fig. 3; lane 3). However, these amplicons remained undigested by Hinc II (Fig. 3; lane 4). We found no intraspecific variation among the RFLP patterns for any of the amplicons $(n=5)$.

The percentage of infection within groups of crabs with similar carapace size was significantly different $(P=0.03$; Table 1$)$. A higher infection rate was observed in crabs with a carapace width $>3.6 \mathrm{~cm}$, and the highest number of infected crabs was found within 3.6-4.4 cm carapace size groups. The largest number of metacercariae was found in a single male crab measuring $4.3 \mathrm{~cm}$, which had 32 metacercariae. The smallest crab of our sample was a female measuring $1.6 \mathrm{~cm}$ and had 2 metacercariae, whereas the largest crab was a female, measuring $5.7 \mathrm{~cm}$, in which only 1 metacercaria was found. We found a statistically significant effect of carapace size on the number of metacercariae under the Poisson regression model (intercept $=-2.42$, standard error $=0.34$; slope $=0.86$, standard error $=0.074, P<0.001$; Fig. 4).

\section{DISCUSSION}

The results of this study confirm the presence of the lung fluke P. mexicanus in the Pedernales area in Manabí Province, Ecuador. Furthermore, the 2 children who were diagnosed with pulmonary paragonimiasis by sputum examination and successfully treated with praziquantel in Quito were autochtho- 
nous cases infected in the Cheve community. The high rate of metacercarial infection found in crabs (52.0\%) represents a potential risk for residents and visitors for acquiring $P$. mexicanus infections because it is a common practice to eat raw or undercooked crabs in this region.

The crab, H. guayaquilensis, which has been reported from this study area [15] is reported here as a suitable second intermediate host for $P$. mexicanus, and this is a new host record. Previous studies have described 2 freshwater crab species in the same genus, namely $H$. aequatorialis and $H$. chilensis (formerly referred to as Strengeria eigenmanni and then Pseudothelphusa chilensis), as second intermediate hosts for P. mexicanus in Manabí Province [7]. Although, P. ecuadoriensis was described as the lung fluke species in Ecuador [6], it was later considered a junior synonym of $P$. mexicanus $[4,7]$. However, recent evidence has proposed that the individuality of P. ecuadoriensis should be reconsidered based on molecular and morphological evidence [5]. Further molecular studies are necessary to obtain a reliable consensus on the taxonomy of $P$. mexicanus and P. ecuadoriensis in Ecuador [5]. Based on the molecular methods used here (sequencing, and PCR-RFLP using Hinc II), we confirmed that the metacercariae examined belonged to P. mexicanus. The molecular region selected for PCR-RFLP did not produce an identifiable pattern in $P$. kellicotti from the USA and $P$. caliensis from Costa Rica $[13,16]$, suggesting that PCR-RFLP using Hinc II can be used as a tool to discriminate P. mexicanus from these 2 other American lung fluke species, although P. caliensis specimens were unavailable for our analysis.

The infection rate of excysted metacercariae in crabs found here differs from that reported in previous studies performed in Manabí Province. For example, an infection rate of 100\% was found in the crab H. aequatorialis in Jipijapa [6], whereas the infection rate was $16.1 \%$ in $H$. chilensis in Nalpe (Fig. 1) [10]. This difference in infection rates might be due to the different crab species acting as hosts. In addition, environmental factors, such as the deforestation that occurred over the years, might have changed the habitats of the reservoirs and intermediate hosts for P. mexicanus. Furthermore, the contamination of rivers with insecticides, fungicides, and other chemicals used by cattle ranches, coffee, cocoa, and African palm plantations, can directly affect the survival of the intermediate hosts, as mentioned in studies carried out in the neighboring Esmeraldas Province [10]. The high natural infection rate of 52\% found in the present study might be related to the fact that primary forests in mountains and water sources of streams have remained uncontaminated. The livelihood of the reservoir animals including the first and second intermediate hosts (a mollusk, and crustacean, respectively) might not be threatened, and thus the life cycle of $P$. mexicanus is properly maintained in the area surrounding the Cheve River.

A statistical difference in infection rate was found between crab groups of different carapace sizes (Table 1). Furthermore, the likelihood ratio test under the Poisson regression model showed a significantly positive relationship between crab size and number of metacercariae $(P<0.001$, Fig. 4). These data suggest that large crabs are heavily infected with $P$. mexicanus in the Cheve River. This relationship was first described in Esmeraldas Province [10]. Larger crabs are more valuable as food by people because they have more meat. If the local residents maintain the habit of eating raw or undercooked crabs, the probability of finding more individuals with paragonimiasis might increase.

The high natural infection rate of crabs with Paragonimus metacercariae, the abundance of crabs in the area, the ease of their capture, and the habit of local residents of consuming raw or undercooked crabs represent potential risk factors for the acquisition of paragonimiasis. The dissemination and familiarization of the results of the present study by the public health government agencies is important for implementing preventive measures or programs. Physicians and health personnel must consider the diagnosis of paragonimiasis in patients with pulmonary symptoms coming from this area, and thus make an early diagnosis and a timely treatment.

\section{ACKNOWLEDGMENTS}

This study was supported by JSPS KAKENHI Grants (nos. 25305011 and 16H05820). We thank Dr. Ronald Guderian for reviewing the paper. We also thank Dr. Masatsune Takeda, Emeritus Professor of the National Museum of Nature and Science, Tsukuba, Japan, for his expert advice on the identification of the freshwater crabs, and Prof. John Kelly from the University of Kansas for his advice on statistical approaches. Further thanks to Dr. Peter U. Fischer and Prof. Gary J. Weil of the Washington University School of Medicine, St. Louis, USA, and Prof. Timothy P. Yoshino of the University of Wisconsin, School of Veterinary Medicine, Madison, USA, for their critical support in collecting samples and invaluable suggestions. Last but not the least, we thank Dr. Stefan Hannus, Intana Bioscience GmbH, Planegg, Germany, for his assistance in manu- 
script translation and discussion.

\section{CONFLICT OF INTEREST}

We have no conflict of interest related to this work.

\section{REFERENCES}

1. Acha P, Szyfres B. Zoonosis y Enfermedades Transmisibles Comunes al Hombre y a los Animales: Volumen III. Parasitosis. 3rd ed. Washington DC, USA. Organización Panamericana de la Salud. 2003, p 158-164.

2. Iwagami M, Monroy C, Rosas MA, Pinto MR, Guevara AG, Vieira JC, Agatsuma Y, Agatsuma T. A molecular phylogeographic study based on DNA sequences from individual metacercariae of Paragonimus mexicanus from Guatemala and Ecuador. J Helminthol 2003; 77: 33-38.

3. Waikagul J, Lazo R, Cornejo E, Lazo M, Llaguno M, Barrezueta J, Llaguno M, Botta M, Yoonuan T, Akahane H. Paragonimus infection in Pedernales, Ecuador. Bull Central Res Inst Fukuoka Univ, Series E, Interdisc Sci 2003; 1: 259-273.

4. Miyazaki I. Paragonimiasis Mexicana. In Miyazaki ed, An illustrated book of helminthic zoonoses. Tokyo, Japan. Southeast Asian Medical Information Center. 1991, p 125-129.

5. López-Caballero J, Oceguera-Figueroa A, León-Règagnon V. Detection of multiple species of human Paragonimus from Mexico using morphological data and molecular barcodes. Mol Ecol Resour 2013; 13: 1125-1136.

6. Voelker J, Arzube R. Ein neuer Lungenegel aus der Küstenkordillere von Ecuador: Paragonimus ecuadoriensis n. sp. (Paragoninidae; Trematoda). Tropenmed Parasit 1979; 30: 249-263.

7. Calvopiña M, Romero D, Castañeda B, Hashiguchi Y, Sugiyama H. Current status of Paragonimus and paragonimiasis in Ecuador.
Mem Inst Oswaldo Cruz 2014; 109: 849-855.

8. Ministerio del Ambiente del Ecuador (MAE). Sistema de Clasificación de los Ecosistemas del Ecuador Continental. Quito, Ecuador. Subsecretaría de Patrimonio Natural. 2012.

9. Sugiyama H, Singh TS, Rangsiruji A. Paragonimus. In Liu DY ed. Molecular Detection of Human Parasitic Pathogens. Florida, USA. CRC Press. 2013, p 423-436.

10. Vieira JC, Blankespoor HD, Cooper PJ, Guderian RH. Paragonimiasis in Ecuador: prevalence and geographical distribution of parasitisation of second intermediate hosts with Paragonimus mexicanus in Esmeraldas Province. Trop Med Parasitol 1992; 43: 249-252.

11. Bowles J, Blair D, McManus DP. A molecular phylogeny of the human schistosomes. Mol Phylog Evol 1995; 4: 103-109.

12. Blair D, Agatsuma T, Watanobe T, Okamoto M, Ito A. Geographical genetic structure within the human lung fluke, Paragonimus westermani, detected from DNA sequences. Parasitology 1997; 115: 411-417.

13. Fischer PU, Curtis KC, Marcos LA, Weil GJ. Molecular characterization of the North American lung fluke Paragonimus kellicotti in Missouri and its development in Mongolian gerbils. Am J Trop Med Hyg 2011; 84: 1005-1011.

14. Calvopina M, Romero-Alvarez D, Macias R, Sugiyama H. Severe pleuropulmonary paragonimiasis caused by Paragonimus mexicanus treated as tuberculosis in Ecuador. Am J Trop Med Hyg 2017; 96: 97-99.

15. Takeda M, Sugiyama H, Kumazawa H, Romero-Alvarez D, Calvopina M. Recent collections of freshwater crabs from the Pacific and Amazonian regions of Ecuador, South America. J Teikyo Heisei Univ 2016; 27: 1-16.

16. Hernández-Chea R, Jiménez-Rocha AE, Castro R, Blair D, Dolz G. Morphological and molecular characterization of the metacercaria of Paragonimus caliensis, as a separate species from P. mexicanus in Costa Rica. Parasitol Int 2017; 66: 126-133. 